\title{
Sriya Kumarasinghe Cultural Contingencies on Performance: Empirical findings from business organizations in Sri Lanka, Australia and New Zealand (LAMBERT Academic Publishing, December 2011).
}

\author{
Khondaker Mizanur Rahman \\ (Nanzan University)
}

\section{INTRODUCTION}

Prima facie corporate culture, organisational structure, and management strategy play a pivotal role in the performance of any business enterprise irrespective of its national identity, place of operation, finance and production portfolio, and marketing mix. Increasingly and historically an enormous research is being undertaken and published every year all over the globe to deliberate on the diverse aspects of the above three dimensions. Over fifteen years or so Sriya Kumarasinghe has conducted research from different platforms and statuses, such as PhD researcher under Monbusho scholarship at University of Tsukuba of Japan, graduate student and lecturer at university in Sri Lanka, and casual and regular lecturer at University of Otago in New Zealand. The combined result of these research has been published by LAMBERT Academic Publishing with an ISBN 978-3-8473-0739-6 in December 2011. The size of this book is 130 pages (viiip. +122 p.).

It is a matter of great joy for an author if his/her research finds outlets for publication and thus come to the readers at large. Sriya at first deserves admiration from this reviewer for her relentless work over the years to publish this book. Thanks to LAMBERT Academic Publishing also which excels in the publication of academic works of both novice, mediocre, and even established researchers and authors. This article reviews in a nutshell the contents of this book, examines its academic value, and outlines some drawbacks of the research with a strong expectation that the author will take these into account seriously while conducting research in the future.

\section{ORGANIZATION AND CONTENTS}

This book is composed of the outcomes of three empirical studies that were conducted, firstly to examine organization aspects which enhance business performance, secondly to examine middle managers perception on their leaders that influence the relationship between management process and performance, and thirdly to examine the influence of selecting entry mode strategies and staffing pattern on performance. The outcomes of these three studies have been combined in to this book as follows. 


\section{Chapter 1 Introduction}

1.1. Background

1.2. Objective of the study

1.2.1. Theoretical contribution

1.2.2. Empirical contribution

1.3. Structure of the study

Chapter 2 Theoretical background and research contexts

2.1. Behaviour of modern corporations

2.1.1. Strategy-structure debate

2.1.2. Culture as a moderating factor

2.2. Theoretical perspectives on multinational corporations

2.3. Dunning's OLI Model (Eclectic Paradigm)

2.3.1. Ownership advantages

2.3.2. Location advantages

2.3.3. Internalization advantages

2.4. Resource-based view (RBV) vs. Strategybased view (SBV)

2.5. Risks and control in FDI

2.6. Contingency theory and performance

2.6.1. Contingency theory and human behavior

2.6.2. Contingency theory and a knowledgebased view of management

2.6.3. Contingency theory and agency theory

2.6.4. The concept of .fit

2.7. Research contexts

2.7.1. Sri Lanka and its environment

2.7.2. Colombo Stock Exchange

2.7.3. Profile of New Zealand

2.7.4. Profile of Australia

Chapter 3 Influence of corporate culture, structure, and strategy on organizational performance: An empirical study of business organizations in Sri Lanka

3.1. Introduction

3.2. Core themes and hypotheses

3.2.1. Organizational culture

3.2.2. Organizational structure

3.2.3. Organizational strategy

3.2.4. Theoretical integration

3.3. Research design and methodology

3.3.1. Research framework

3.3.2. Data sample

3.3.3. Questionnaire design

3.3.4. The analytic model
3.4. Analysis and discussion

3.5. Conclusion and limitations

Chapter 4 Middle managers and their leaders: How do they link together for better performance? An investigation on business organizations in Sri Lanka

4.1. Introduction

4.2. Theoretical background

4.2.1. Leadership

4.2.2. National culture, collectivism and individualism

4.2.3. Middle managers

4.2.4. Communication

4.2.5. Decision making

4.3. Research design and methodology

4.3.1. Conceptual framework for study 2

4.3.2. Sample

4.3.3. Independent variables

4.3.4. Dependent variables

4.3.5. Interactions

4.3.6. Control variables

4.3.7. Reliability measures

4.4. Empirical analysis and discussion

4.5. Conclusion and limitations

Chapter 5 Entry mode strategies and performance of Japanese MNCs in Australia and New Zealand: The role of Japanese employees

5.1. Introduction

5.2. Theoretical background

5.2.1. The choice of entry mode

5.2.2. Industry

5.2.3. Staffing policies of Japanese subsidiaries

5.3. Research design and methodology

5.3.1. Conceptual framework

5.3.2. Sample

5.3.3. Dependent variables

5.3.4. Independent variables

5.3.5. Control variable

5.4. Analysis and discussion

5.5. Conclusion and limitations

\section{Chapter 6 Conclusions and implications}

6.1. Summary

6.2. Implications for managers, investors, and policy makers

6.3. Future research 
The central theme of this book is how organizational performance can be improved in the developing business world of Sri Lanka. For this purpose, the author has examined organizational behavior within Sri Lanka. Additional exploration is conducted on business practices of Japanese subsidiaries in Australia and New Zealand. As the author claimed, the latter investigations are done to identify some useful reference strategies for Sri Lankan businesses. Throughout this adventure, she has attached careful attention to extract the mediating effects of organizational culture and national culture on business performance.

After introducing the research agenda and its background in Chapter 1, the author proceeds to examine the theoretical background and context of the research in Chapter 2. Here, she delves in to the strategy-structure debate that prevails historically in management literature.

For Studies 1 and 2 in Chapters 3 and 4 respectively, the author collected behavioral data from middle-level managers in 121 businesses in Sri Lanka, using a questionnaire survey. Among those companies, 91 were listed in Colombo Stock Exchange, and 30 firms were non-listed. For Study 3, she conducted archival based empirical research on Japanese MNCs' subsidiaries in Australia and New Zealand.

Study 1 investigated the influence of organizational culture, structure, and strategy on business performance to see the fit between these three aspects for better performance in the 91 listed companies. Regression analysis was done to measure the predictability of performance. Here the dependent variables were quantitative financial measures and the independent variables were the responses to the questionnaire on culture, structure, and strategy. Findings revealed that dynamic and changing organi- zational structure was a positive indicator of performance. High performers had more waste control mechanisms in production processes and good staff training programs. However, the interaction between culture and structure showed a negative effect on performance.

Study 2 aimed at examining how middle managers' perceptions on their leaders' affect the relationship between management process and performance in all 121 sample companies. It analyzed the mediating effect of leadership style, as perceived by the middle managers, on group decision making and communication as well as its influence on performance. In this case, the dependent variables consisted of both quantitative and qualitative performance outcomes. Results from the regression analysis showed that organizations had positive and significant influence of horizontal communication and group decision making on quality, return on investment, and sales growth. Furthermore, under collectivistic leaders, the performance indicators of quality, service, and innovation were positively influenced by organizational communication and group decision making processes.

Study 3 in Chapter 5 examines the entry mode strategies, staffing and performance of Japanese MNCs in Australia and New Zealand. Data was collected on 275 of Japanese subsidiaries in Australia and New Zealand from Kaigai Shinshutsu Kigyou Souran of Toyo Keizai databank. These sample subsidiaries invested in these two countries from 2003 to 2008. As the dependent variable was dichotomous (gain=1, 0 otherwise) therefore, logistic regression was applied. The independent variables were initial entry mode, ownership, industry category, and staffing policy. Company's duration of operation was also used as a control variable. Findings revealed 
that strategic selection of industry and whollyowned ownership strategy contributed positively towards performance of Japanese subsidiaries in Australia and New Zealand. However, the employment of Japanese staff did not make any significant difference in the financial performance for those subsidiaries in both countries.

\section{ACADEMIC AND PRACTICAL CONTRIBUTIONS OF THIS BOOK}

As the author claims and envisions, empirical findings from the three studies as depicted in this book would have managerial implications for introducing structural and strategic changes effectively in business enterprises without much impact on the organizational culture. Also, organizations with strategic, structural, and cultural fit would demonstrate enhanced performance. Effective middle management and congenial national culture would produce better results for enterprises and/or management. As argued, in collectivistic cultures, middle managers facilitate communication and decision making more effectively. Another highly ambitious argument is that these findings would provide insights in to understanding the relationship between organizational culture and national culture in Sri Lanka, especially. It further emphasizes that the selection of strategic industries and right ownership structures would produce better competitive advantages.

In terms of research methodology, the author has applied a Likert style questionnaire survey with four-point scale in Study 1 (Chapter 3) and tested hypothesis to draw conclusion. She administered the same questionnaire to survey middle managers and also used financial and non-financial data and applied Cronbach Alpha test to measure reliability (Study 2 in Chapter
4). Further, in Study 3 (Chapter 5), in order to examine the influence of entry mode on performance in Japanese MNCs in Australia and New Zealand, she applied logistic regression analysis to test the research proposition. Given the research question and the hypothesis postulated, these methods are reasonably sound. The author has tried to defend all weaknesses in these studies with theoretical and/ or logical arguments. As the author says, "Findings from research are of course subject to a number of limitations. While great care was taken to validate the survey instrument, the difficulty of obtaining reliable data through a questionnaire survey is acknowledged. A larger sample of organizations and multiple respondents representing each organization is also needed to generalize the findings". Very few scholars give such candid attestation to loopholes in own research. This rather increases interests in the readers to this book.

\section{SOME CRITIQUES}

Behaviors of modern corporations have been observed based on the studies of Barnard, Simon, Cyert, and March. Although these are seminal works and have founded the basis of many research until today, it is beyond doubt that these studies are mostly dated. Likewise, references used in other parts are also dated and do not take into account current research. As business environment changes, organizational structure, management strategies, and management behaviors and practices also drastically transform. Perhaps the author could do a better job by investigating more recent literature.

Secondly, in her adventure to explore a model for Sri Lanka, the author refers to Australia, Japan, and New Zealand, and studies the entry mode strategies and behavior of the Japanese 
subsidiaries and influences of those strategies, behavior, and cultural factors on performance. Given the different levels of development of Sri Lanka vs Australia, Japan, and New Zealand, here the question comes to the forefront is, is the match between the environmental and practical aspects of management in the three reference countries suits to the management issues, needs, and environments in Sri Lanka. This country being a British colony and a core member of British Commonwealth might have scope to learn from managerial practices in other Asian countries where British, American, and Japanese MNCs management practices have exhibited very admirable results.

Thirdly, the author's contention of theoretical and empirical contributions of this research cannot be claimed to be completely new and foolproof. Innumerable research shows that culture is only one of the many factors that influence performance. Especially, the level of technology, R\&D, effective shop-floor management, effective tie up between production and marketing departments, balanced sharing of authority and responsibility, top management's ambition and challenge, and employee training and education, effective personal management, etc. highly influence performance in both national and multi-national enterprises. Perhaps, research on a 'systems approach to performance' may produce better research outcomes with practical and theoretical implications.

\section{CONCLUDING REMARKS}

However, these or similar criticisms do not diminish the value of this academic work much. Perhaps, the author needs some more thoughtfulness in her future research especially in selecting the right reference countries for comparison. That might produce more practical values of her research agenda, i.e., to fill up the research gap that she perceived to exist and to offer suggestions to develop a business management model that would successfully respond to the challenges that Sri Lankan companies face at this moment. 